\title{
3 LANDFILL LEACHATE TREATMENT - TOWARDS AN INTEGRATED APPROACH
}

Markku Pelkonen Helsinki University of Technology, PO BOX 6100, FIN02015 HUT, Finland

\begin{abstract}
Full-scale results during two years operation in a controlled activated sludge system with nitrogen removal show that nitrification can be managed around the year, even long periods at low temperature $\left(4-5^{\circ} \mathrm{C}\right)$, which is a new feature in landfill leachate management. The total nitrogen removal was $46-57 \%$ as annual averages and was limited seasonally by the low carbon content of leachate. Addition of external carbon was also tested. The removal of heavy metals was reasonable $(45-90 \%)$, but organohalogen compounds was removed only partially (around $20 \%$ ). The biological step suits for the first phase of local treatment and rather low costs can be achieved. If more stringent effluent standards are required, a post treatment system can be added - some of the most suitable alternatives and their costs are discussed. From environmental point of view more comprehensive alternatives should be considered, which means the integration of processes inside the landfill body to the whole treatment system.
\end{abstract}

\section{KEYWORDS}

Landfill leachate, nitrogen removal, low temperature, metals, organohalogen compounds, post treatment, landfill management

\section{INTRODUCTION}

In Finland local leachate treatment is an option under development, because there are not many full- scale examples of effective treatment in such systems. Mainly the leachate is treated in municipal wastewater treatment plants or in local treatment systems with low cost and low performance such as simple filtration.

The main leachate components in consideration are organic compounds as COD and BOD, nutrients especially nitrogen, which is the most important component for eutrophication in long term (Pelkonen et al. 2000), toxic compounds such as heavy metals and organic halogen compounds (AOX) and salts. Biological treatment can be applied to remove most of those compounds at least partially, but in Nordic conditions the temperature can be rather low and should be considered as a limiting factor. 
Examples of the effective treatment of leachate in Finland based on local solutions are evaporation (two plants) and activated sludge system with nitrogen removal (one plant). The results of a development work concerning biological treatment are discussed below.

\section{BIOLOGICAL TREATMENT OF LEACHATE}

Biological treatment is a leachate treatment option with large variation of cost level and performance. There are such low cost applications, which necessarily do not work in demanding conditions as Nordic ones, because of the temperature effect. Pond like activated sludge system is one example of less efficient treatment (Lehto, Pelkonen 1996). These experiences led to a development of a new process realisation, which was first operated in pilot scale and the results gave the basis for the full-scale plant design (Pelkonen et al. 1999). The process in consideration is an activated sludge system with nitrogen removal and aimed at least a partial removal of harmful organic compounds such as AOX. The evaluation of the full scale plant operation from the first two years is an important topic of this paper.

\subsection{Full scale performance of a new process}

The water is coming from a landfill, the area of which is 2.5 hectars, and from a windrow composting area of one hectar. The average flow is approximately $50 \mathrm{me} / \mathrm{d}$ and maximum design daily flow is $100 \mathrm{~m}^{3} / \mathrm{d}$. The operational range of the process varies rather much, and in spite of equalization basin of $5000 \mathrm{~m}^{3}$ volume, flow rates to the treatment plant are higher in springtime during snow melting period and autumn after longer periods of rain. One the other hand during summer and winter there can be longer periods with a low flow rate. The process performance in full scale is shown in tables 1 and 2 and in Figure 1.

Table 1. Influent and effluent concentrations in a full-scale nitrogen removing activated sludge plant

Period January- October 2001 (number of observations 12 - 14)

INFLUENT

CODtot

CODfil

BOD7

Ntot

NH4-N

$\mathrm{NO} 2+\mathrm{NO} 3-\mathrm{N}$

PO4-P

Process temperature

\begin{tabular}{rrrrrrrrr} 
Ave & \multicolumn{10}{c}{ EFFLUENT } \\
577 & 232 & 330 & 1020 & 148 & 17 & 130 & 190 \\
510 & 231 & 230 & 880 & 133 & 13 & 110 & 150 \\
191 & 112 & 36 & 350 & 6,8 & 4,6 & 2 & 16 \\
96 & 21,7 & 58,1 & 127,3 & 40,8 & 14,5 & 17,2 & 58,3 \\
84 & 18,6 & 50,6 & 110 & $<0,2$ & & \multicolumn{3}{c}{$<0,2$} \\
& & & & 37,6 & 15,2 & 14,2 & 61,1 \\
& & & & 0,9 & 0,7 & 0,1 & 2,7
\end{tabular}

$\begin{array}{llll}10,5 & 5,7 & 4,4 & 20,8\end{array}$ 
Table 2. Removal efficiency in a full-scale nitrogen removing activated sludge plant Period as in Table 1, except AOX and metals (period $1^{\text {st }}$ half 2000, Pelkonen et al 2000)

\begin{tabular}{|c|c|c|c|c|}
\hline \multicolumn{5}{|c|}{ ave stdev min $\max$} \\
\hline CODtot & 70,2 & 12,4 & 53,8 & 86,8 \\
\hline CODfil & 67,9 & 5,7 & 36,0 & 85,8 \\
\hline BOD7 & 93,4 & 7,8 & 76,3 & 99,4 \\
\hline Ntot & 56,5 & 19,8 & 28,8 & 83,2 \\
\hline NH4-N & $>99$ & & & \\
\hline $\mathrm{AOX}$ & 20 & & & \\
\hline Al & 66 & & & \\
\hline $\mathrm{Cd}$ & 64 & & & \\
\hline $\mathrm{Cu}$ & 80 & & & \\
\hline $\mathrm{Pb}$ & 80 & & & \\
\hline $\mathrm{Ni}$ & 42 & & & \\
\hline $\mathrm{Zn}$ & 69 & & & \\
\hline $\mathrm{Fe}$ & 91 & & & \\
\hline
\end{tabular}

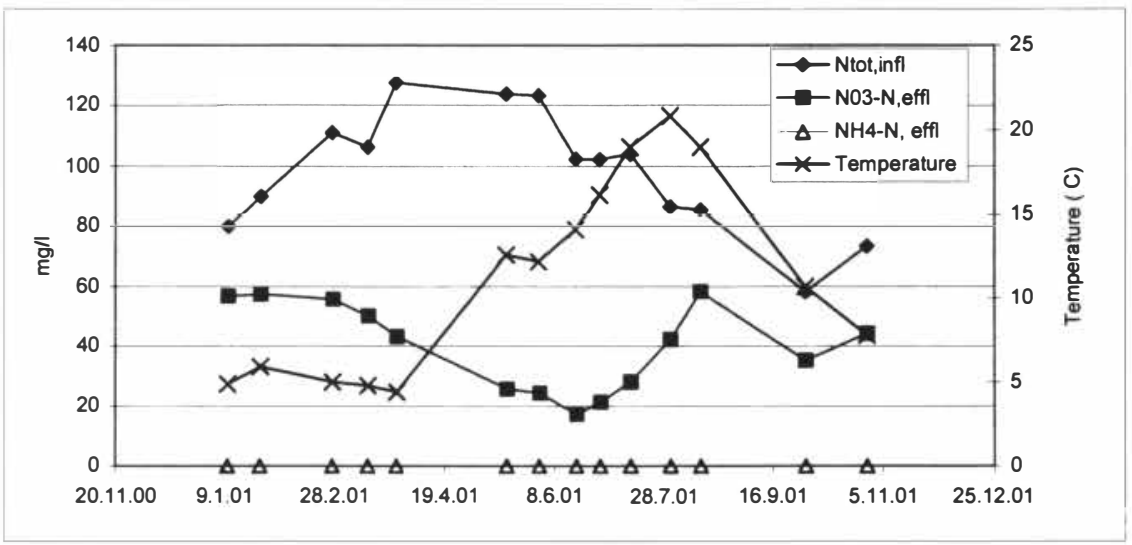

Fig 2. Time series of some influent and effluent concentrations at the examined full-scale plant

The removal efficiency of organic matter as $\mathrm{BOD}_{7}$ was good, over $90 \%$ and the residual organic matter (as COD) was below $200 \mathrm{mg} / \mathrm{l}$, which can be considered as unbiodegradable. The efficiency of nitrogen removal in form of ammonia oxidation was good, over $99 \%$ in average and without difficulties during the periods when the process temperature is $4-6{ }^{\circ} \mathrm{C}$, as can be seen in the Figure 1. Data from the previous year was similar to this and hence the ammonia oxidation at low temperature conditions can be considered as a well performing possibility also in long term.

The total nitrogen removal was in average $57 \%$, which can be considered as a reasonable result. During the previous year it was lower - $46 \%$ - and its variation was rather high (30 - 
$80 \%)$ due to the variation of carbon concentration in the leachate. In the denitrification phase carbon is needed and at $\mathrm{BOD}_{7}$-values below $150 \mathrm{mg} / \mathrm{l}$ the denitrification efficiency was limited. Because of this some experiments were done by adding external carbon source, which resulted in higher nitrogen removal efficiency $(50-70 \%)$. The concentration of carbon in leachate was dependent on seasons.

Also the effluent solids concentration was low, which relates to the heavy metal removal efficiency, which can be considered as a considerable one (Table 1). On the other hand, removal of organic matter in form of AOX varied considerably and was directly related to the temperature. During higher temperature periods (over $15^{\circ} \mathrm{C}$ ), the AOX removal efficiency was $30-50 \%$ depending on the biodegradable fraction. In winter conditions and low water temperature, the AOX removal efficiency was much lower, 5-20\%. Hence the temperature effect can be seen in the effluent water quality nearby only in the decreased efficiency of AOX removal, not in other parameters.

The results show that with this type of system most landfill leachate components can be removed with a high or reasonable efficiency. The costs of this process are reasonable, approximately 2-2,5 euros $/ \mathrm{m} 3$, or less than 12 euros/m3 removed $\mathrm{kg} \mathrm{NH} 4 \mathrm{~N}$ (based on design load) (Pelkonen et al. 2000, 1999).

Therefore the nitrogen removing biological process based on the activated sludge system is a basis and the process can be enhanced as leachate characteristics and effluent standards requires.

The possible more stringent requirements would concern effluent $\mathrm{COD}$ and harmful organic substances (AOX). The enhanced COD removal would require additional processes, but the AOX removal can be managed in some extent with the aid of elevated temperature. In this way the AOX removal efficiency can be maintained approximately at the level of $30-50 \%$ in the examined leachate quality, which reflects only one case.

\section{COMBINED TREATMENT OPTIONS TOWARDS AN INTEGRATED APPROACH}

When it is question of higher effluent standards than can be achieved in a well controlled biological system as mentioned before, there are alternatives to introduce some post treatment systems, such as oxidation (possible included with an additional biological process), granular activated carbon filtration (GAC) or a membrane process. Evaporation is also one alternative to achieve high effluent standard, but it does not suit to remove volatile compounds such as volatile fatty acids (VFA) and requires hence some combination of nearest some biological process, if fatty acids are present in the leachate.

A more comprehensive view is to incorporate the landfill body and processes occurring in the waste matrix by leachate recirculation.

The efficiency of a GAC-filtration step in COD removal is remarkable and gives a high enough effluent quality in the most stringent limits as that of Germany which is $200 \mathrm{mg} / \mathrm{l}$. The removal efficiency can be up to $60-70 \%$, but depends on the degree of adsorption, spcific load and material quality etc.

The cost of GAC-filtration depends on the quality of water and the filter material and should be evaluated in each specific case. However, it seems likely that with reasonable costs the filtration alternative is worth considering. 
The oxidation is found to be an effective but rather expensive alternative (Theilen 1995) and therefore less widely used in full-scale applications. However there are also less expensive and less energy intensive alternatives than UV combined with hydrogen peroxide oxidation, such as Fenton oxidation. Preliminary laboratory scale results show that these alternative methods can achieve reasonable COD and AOX removal and the estimated costs will be at a more realistic level.

Membrane processes have been applied in some extent integrated with the biological system as a membrane bioreactor, which gives advantages in better solids separation. On the other hand this type of process does not necessarily lead to a better degradation of organohalogen compounds (AOX) than in a typical activated sludge process (Krauth 1993). A membrane step can be applied after the biological step separately and nanofiltration is then the most probable alternative. However there are rare full-scale applications of this combination and if a reverse osmosis system is applied, the system cost will rapidly increase.

When the landfill leachate management is viewed in a more comprehensive way, the landfill should be looked as a whole system including also a longer time perspective of the leachate emissions. To combine the processes going on in the waste matrix and an external leachate treatment system, this can lead to recirculation of nitrates to landfill body and hence to remove nitrates from the leachate. Another alternative is to enhance the waste degradation process in such a way that leachate quality will be better suitable to the external (biological) treatment processes. One example in this direction is a two stage degradation system with an acidogenic phase, which leads also to a faster withdrawal of emissions (Lagerkvist 2000). As a whole the environmental benefits in this type of integration seem to be the highest and such full scale systems should be tested and evaluated more thoroughly. Because the local conditions can affect considerable the results, preferably such integrated approaches should be studied and results evaluated parallel in different circumstances, which gives the opportunity to reach more reliable and comparable results and conclusions.

\section{CONCLUSION}

Results from a full scale leachate treatment plant based on a controlled activated sludge process show that nitrogen removal is possible even at low temperatures, $4-5{ }^{\circ} \mathrm{C}$. The ammonia nitrogen removal was in average over $95 \%$ during the two years operation period, and the total nitrogen removal $46-57 \%$ as annual averages. The ammonia removal was stable at low temperatures for several months.

The denitrification efficiency was periodically limited by low content of biodegradable carbon, which indicates changes in the landfill body towards methane phase and decreasing concentrations of carbon in water phase at this eight years old landfill.

The removal of heavy metals in the activated sludge process was reasonable (45-90\%), and these compounds seem not to be a problem. More concern should be paid on the harmful organic compounds, such as AOX. The removal efficiency of AOX was in average $20 \%$, but was clearly affected by the low temperature (range $5-50 \%$ ). 
If more stringent effluent requirements are applied, the activated sludge process should be adapted as a part of a more complicated treatment system. To enhance the denitrification and total nitrogen removal, carbon concentration should be increased in leachate. External carbon source has been tested, leading to $50-70 \%$ total nitrogen removal. But taking the landfilled waste matrix as the carbon source and controlling the degradation process gives a more integrated approach leading also to a faster withdrawal of emissions.

As a completing system for the biological treatment can be applied activated carbon filtration, oxidation with a possible biological step and membrane filtration. The costs of the biological treatment alone were estimated to be $2-2,5$ euros $/ \mathrm{m}^{3}$, which shows that local treatment can be a true alternative for the treatment in municipal treatment plants. But in a local treatment systems the harmful substances can be managed locally by adapting necessary actions in the leachate treatment systems.

The preliminary evaluation of the completing systems show that costs will not increase dramatically and the finalizing step of treatment should be integrated to the system aiming at removal of target compounds according to regulations and local conditions.

\section{REFERENCES}

1. Krauth K (1993) .Sickerwasserreinigungsanlage der Deponie Billigheim. In: Kayser R (ed.) Sickerwasser aus Muelldeponien- vermeiden - verhindern - behandeln. TU Braunschweig, ZAF Heft 8.

2. Pelkonen M, Kotro M, Wang Z (2000) Full-scale performance of biological leachate treatment at low temperature. $1^{\text {st }}$ intercontinental landfill research symposium, 10 13.12.2000, Luleå, Sweden.

3. Pelkonen M, Rauta E, Tanskanen J-H (2000) Yhdyskuntajätehuollon päästöjen järjestelmätarkastelu (Examination of emissions in municipal solid waste system) Helsinki Univ. of Technology, Laboratory of Env. Eng., Report 21.

4. Lagerkvist A (2000) Experiences of acidogenic treatment of waste in landfill environments. $1^{\text {st }}$ intercontinental landfill research symposium, $10-13.12 .2000$, Luleå, Sweden

5. Lehto M, Pelkonen M (1996) Nurmijärven mallikaatopaikan suotovedet ja niiden käsittely. (Leachates and their treatment at Numrijärvi model landfill). Vesitalous Vol 37, No 1, p. 21 26.

6. Theilen U (1995). Behandlung von Sickerwasser aus SiedlungsabfalldeponienBetriebsergebnisse und Kosten grosstechnischer Behandlungsanlagen. Veröffentlichungen Des Institutes fuer Siedlungswasserwirtschaft und Abfalltechnik der Universität Hannover. Heft 91.353 p.

7. Pelkonen M, Kotro M, Rintala J (1999b): Biological nitrogen removal from landfill leachate: a pilot scale study. Waste Management \& Research 17, 493-7. 